\title{
Free Short-Period Internal Waves in the Arctic Seas of Russia
}

\author{
A. A. Bukatov, N. M. Solovei ${ }^{\bowtie}$, E. A. Pavlenko \\ Marine Hydrophysical Institute of RAS, Sevastopol, Russian Federation \\ 凶e.le.7@hotmail.com
}

\begin{abstract}
Purpose. The aim of the work is to investigate vertical structure and phase characteristics of free short-period internal waves (IW), and to assess their dependence on density stratification in the Barents, Kara, Laptev and East Siberian seas.

Methods and Results. Solving the main boundary problem of the Sturm - Liouville theory resulted in calculating the amplitudes of velocity vertical component, own frequencies and periods of the first mode of internal waves. The density field was calculated using the reanalysis data (World Ocean Atlas 2018) on temperature and salinity for $1955-2017$ with a resolution $0.25^{\circ} \times 0.25^{\circ}$. The relation between the internal waves' vertical structure and dispersion features, and the density depth distribution was analyzed. It is shown that the averaged over the sea area depth of the maximum amplitude of the IW velocity vertical component in the Barents and Kara seas is $\sim 90 \mathrm{~m}$ in the mid winter and $\sim 75-80 \mathrm{~m}$ in summer, and in the Laptev and East Siberian seas $-\sim 60 \mathrm{~m}$ throughout the entire year.

Conclusions. In the months when the density gradients are maximal, the internal waves of the highest frequency and the shortest period are observed. The maximum water stability in the Barents Sea takes place in July - August, in the Kara Sea - in July - September and November, in the Laptev Sea - in June, November, and in the East Siberian Sea - in July. Just in the same months, the maximum values of the averaged own frequencies, and the minimum values of the averaged own periods and amplitudes of the vertical component of the internal waves' velocity are observed.
\end{abstract}

Keywords: Barents Sea, Kara Sea, Laptev Sea, East Siberian Sea, buoyancy frequency, internal waves, own frequency, own period, vertical component of velocity

Acknowledgements: the investigation was carried out within the framework of the state task on theme No. 0555-2021-0004.

For citation: Bukatov, A.A., Solovei, N.M. and Pavlenko, E.A., 2021. Free Short-Period Internal Waves in the Arctic Seas of Russia. Physical Oceanography, [e-journal] 28(6), pp. 599-611. doi:10.22449/1573-160X-2021-6-599-611

DOI: 10.22449/1573-160X-2021-6-599-611

(C) A. A. Bukatov, N. M. Solovei, E. A. Pavlenko, 2021

(C) Physical Oceanography, 2021

\section{Introduction}

One of the reasons for the appearance of internal waves (IW) in the ocean is the flow of tidal currents around bottom irregularities that result in periodic vertical displacements of isopycnic surfaces. In the ocean, these disturbances propagate in the form of free internal waves. However, when studying internal waves in the Arctic Basin, it the effect of critical latitude should be taken into account. A latitude close to $75^{\circ}$ is critical for semidiurnal internal waves; to the north of this latitude, IW with a tidal frequency cannot exist in the form of free waves [1, 2]. Their generation mechanism at high latitudes is the same as at low and temperate ones, but at high latitudes the internal tidal wave is destroyed and generates packets of free short-period waves [3]. Several experimental observations of IW are described in the literature. They confirm the existence of internal short-period waves in the Arctic Basin: for example, in [4], IW were noted in the Barents Sea with periods of 15-60 min. 
The present paper is aimed to study free short-period internal waves, the relationship between their vertical structure and phase characteristics with the Brunt - Väisälä frequency distribution over depth in the Barents, Kara, Laptev and East Siberian seas.

\section{Materials and Methods}

To calculate the monthly average values of density, the World Ocean Atlas 2018 reanalysis data on temperature and salinity for the period 1955-2017 at $0.25^{\circ} \times 0.25^{\circ}$ grids with a step of $5 \mathrm{~m}$ in depth to the $100 \mathrm{~m}$ horizon and with a step of $25 \mathrm{~m}$ - to $150 \mathrm{~m}$ horizon $[5,6]$ was used. Research area is $66-82^{\circ} \mathrm{N}, 16-180^{\circ} \mathrm{E}$. The resulting density arrays were checked for inversions and, if necessary, corrected by inversion values' replacement with values interpolated for adjacent horizons [7]. At each grid node, the buoyancy frequency profiles $N(z)$ were calculated. The Brunt - Väisälä frequency maximum in depth $\left(N_{\max }(z)\right)$ and its depth $\left(H N_{\max }(z)\right)$ were determined.

The study of internal waves was carried out based on linear equations of motion of a continuously stratified fluid in the form of Fjeldstad [8], which have a solution in the form of a superposition of plane waves [9]. In particular, the vertical component of the velocity $w(x, y, z, t)(x, y$ are horizontal coordinates, $t$ is time) is represented as follows

$$
w(x, y, z, t)=\sum_{n=1}^{\infty} \iint_{-\infty}^{\infty} W^{(n)}(k, z) \exp \left\{i\left[k_{x} x+k_{y} y-\omega^{(n)}(k) t\right]\right\} d k_{x} d k_{y}
$$

where $\omega^{(n)}(k)$ is the dispersion relation (own frequency) for mode with number $n$ and wave number $k=\left(k_{x}^{2}+k_{y}^{2}\right)^{1 / 2} ; W^{(n)}(k, z)$ is this mode amplitude (eigenfunction). If the Boussinesq approximation is applied, to filter out surface waves and to neglect the Earth rotation, then $W^{(n)}(k, z)$ will be a solution to a boundary value problem of the Sturm - Liouville type with zero boundary conditions at the bottom and free surface of the liquid:

$$
d^{2} W^{(n)} / d z^{2}+\left(\lambda^{(n)} N^{2}-k^{2}\right) W^{(n)}=0, \quad W^{(n)}(H)=W^{(n)}(0)=0,
$$

where $\lambda^{(n)}=\left(k / \omega^{(n)}\right)^{2}, \omega^{(n)}$ is the own frequency; $k$ is the wave number; $H$ is the depth.

For the numerical implementation of the boundary value problem for a given profile $N(z)$, its finite-difference approximation was constructed. The resulting system of linear algebraic equations was solved by a method based on solving the characteristic equation for its matrix [10].

It is known that the first mode makes the largest contribution to the energy spectrum of the wave packet; therefore, the amplitudes of the vertical velocity component $(W(z))$, own frequencies $\left(\omega^{(1)}\right)$ ) and periods $(T)$ of the first mode were considered [11]. To study the dispersion properties of IW, own frequencies were 
calculated for wavelengths $(\lambda)$ in the range of 250-1500 m with a step of $25 \mathrm{~m}$. Presence of waves with lengths of $>250 \mathrm{~m}$ in the Arctic seas is confirmed by radar sensing from space [12]. The detail of IW manifestations in the radar images is limited by the pixel size of $75 \times 75 \mathrm{~m}$, and the minimum distinguishable wavelength is 250-300 m. Waves with shorter lengths in the images in the radar imaging modes indicated in [12] are difficult to determine.

\section{Analysis of the Results}

Despite the close geographical location of the Barents, Kara, Laptev and East Siberian seas, each of them has its own regional features, which are clearly illustrated in Fig. 1. For quantitative characterization and comparison of the intraannual variability of water stratification, the average value of the Brunt - Väisälä frequency maximum $\left(N_{\max }(z)_{\text {average }}\right)$ in depth and the average depth of the maximum $\left(H N_{\max }(z)_{\text {average }}\right)$ for each sea were calculated.
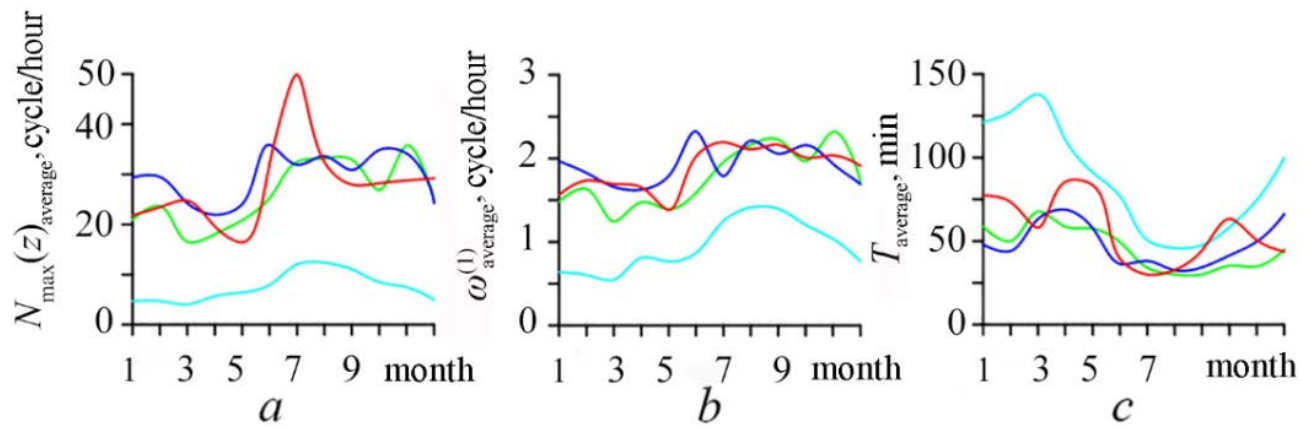

F i g. 1. Intra-annual variation of the averaged over the sea area maximum of the buoyancy frequency over depth (a), own frequency $(b)$ and own period $(c)$ of the first mode at a wavelength $1000 \mathrm{~m}$ for the Barents (turquoise curve), Kara (green curve), Laptev (blue curve) and East Siberian seas (red curve)

It can be seen (Fig. 1, a) that the greatest density gradients in all the seas under consideration are observed in summer months, which is associated with ice melting and an increase in continental runoff. In the Barents Sea, the highest values of $N_{\max }(\mathrm{z})_{\text {average }}$ are $\sim 12.4 \mathrm{cycle} / \mathrm{h}$, in the Kara and Laptev Sea $-\sim 35.8 \mathrm{cycle} / \mathrm{h}$ and in the East Siberian Sea $-\sim 49.8$ cycle/h. The maximum water stability in the Barents Sea occurs in July - August, in the Kara Sea - in July - September and November, in the Laptev Sea - in June and November and in the East Siberian Sea - in July. The $N_{\max }(\mathrm{z})_{\text {average }}$ values in the Barents Sea are several times lower than in other seas. The low water stability in the Barents Sea is explained by the North Cape Current influence. During its movement to the east, the Atlantic waters, having high salinity and temperature, cool and sink, which leads to a smoothing of the difference in density between the layers and to the stable equilibrium loss of the layers [13]. The river runoff into the Barents Sea is inconsiderable; however, almost half of the Kara and Laptev Sea area is located under the influence of continental waters. The decisive role in the formation of the hydrological conditions of these seas belongs to the processes occurring in the zones of mixing 
of surface Arctic waters with river waters. In areas of strong influence of river runoff, as a result of mixing of river and surface Arctic waters, water is formed with a relatively high temperature and low salinity. Large density gradients are created at their interface (horizon 5-10 m) [14]. The continental runoff into the East Siberian Sea does not affect its general hydrological regime significantly, but only determines some hydrological features of the coastal areas in summer. However, the East Siberian Sea is the most ice-covered of the Arctic seas, from October - November to June - July it is completely covered with ice. A significant increase in $N_{\max }(\mathrm{z}$ )average in July is apparently associated with increased ice melting in early summer [15].

Fig. $1, b$ shows the intra-annual variation of the own frequency of the IW first mode $\left(\omega^{(1)}\right.$ average $)$ averaged over the sea area. For a wavelength of $1000 \mathrm{~m}$, the largest $\omega^{(1)}$ average and the smallest own period of the first mode of the IW ( $T_{\text {average}}$ ) averaged over the sea area in the Barents Sea are 1.41 cycle/h and $45 \mathrm{~min}$; in the Kara Sea, 2.31 cycle/h and $30 \mathrm{~min}$; in the Laptev Sea 2.32 cycles/h and 33 minutes and in the East Siberian Sea 2.19 cycles/h and 30 minutes. During the months of maximum density gradients, the highest frequency waves are observed. The correlation coefficient between the intra-annual cycles $N_{\max }(\mathrm{z})_{\text {average }}$ and $\omega^{(1)}$ average exceeds 0.9 for all the seas.

The intra-annual variation of the first IW mode period averaged over the sea area is shown in Fig. 1, $c$. The values of the periods are presented for a wavelength of $1000 \mathrm{~m}$, however, qualitatively, the $T_{\text {average }}$ graph will have the same form for other wavelengths from the range considered. The short-period waves are observed in the Kara and Laptev seas, for which $T_{\text {average }}(\lambda=1000 \mathrm{~m})$ averaged 12-month is 46 and $48 \mathrm{~min}$, respectively, $87 \mathrm{~min}$ for the Barents Sea, $57 \mathrm{~min}$ for the East Siberian Sea. Fig. 1, 2 also show that IW with the shortest periods are observed in the months of the greatest density gradients. The correlation coefficient $(R)$ between the intra-annual cycles $N_{\max }(\mathrm{z})_{\text {average }}$ and $T_{\text {average }}$ is approximately -0.95 for all the seas.
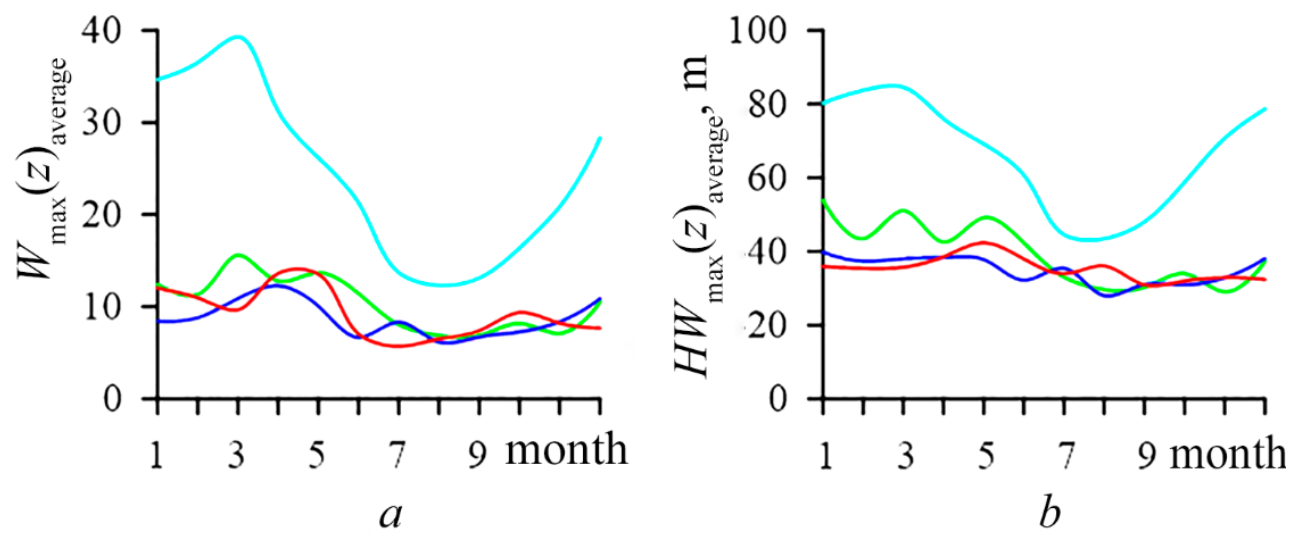

F i g. 2. Intra-annual variation of the averaged over the sea area maximum of the amplitude of the vertical component of the IW first mode velocity (in conventional units) (a) and its depth (b) for the Barents (turquoise curve), Kara (green curve), Laptev (blue curve) and East Siberian seas (red curve) 
To analyze the vertical structure of the IW, the profiles of the amplitudes of the vertical components of the first IW mode velocity were calculated at each node of the grid. Also, the maximum amplitude of the vertical component of the velocity $\left(W_{\max }(z)\right)$ along the depth and the depth of its occurrence $\left(H W_{\max }(z)\right)$ were determined. Then, the $W_{\max }(z)$ and $H W_{\max }(z)$ values obtained for each month were averaged over the sea areas $\left(W_{\max }(z)_{\text {average }}, H W_{\max }(z)_{\text {average }}\right)$ (Fig. 2$)$. It was found that the highest values of $W_{\max }(z)_{\text {average }}$ (more intense wave dynamics) are observed in the months of the lowest density gradients: in the Barents and Kara Seas - in March and in the Laptev and East Siberian seas - in April. The correlation coefficient between the intra-annual cycles $N_{\max }(z)_{\text {average }}$ and $W_{\max }(z)_{\text {average }}$ exceeds 0.9 for all the seas (Fig. 1, 2).
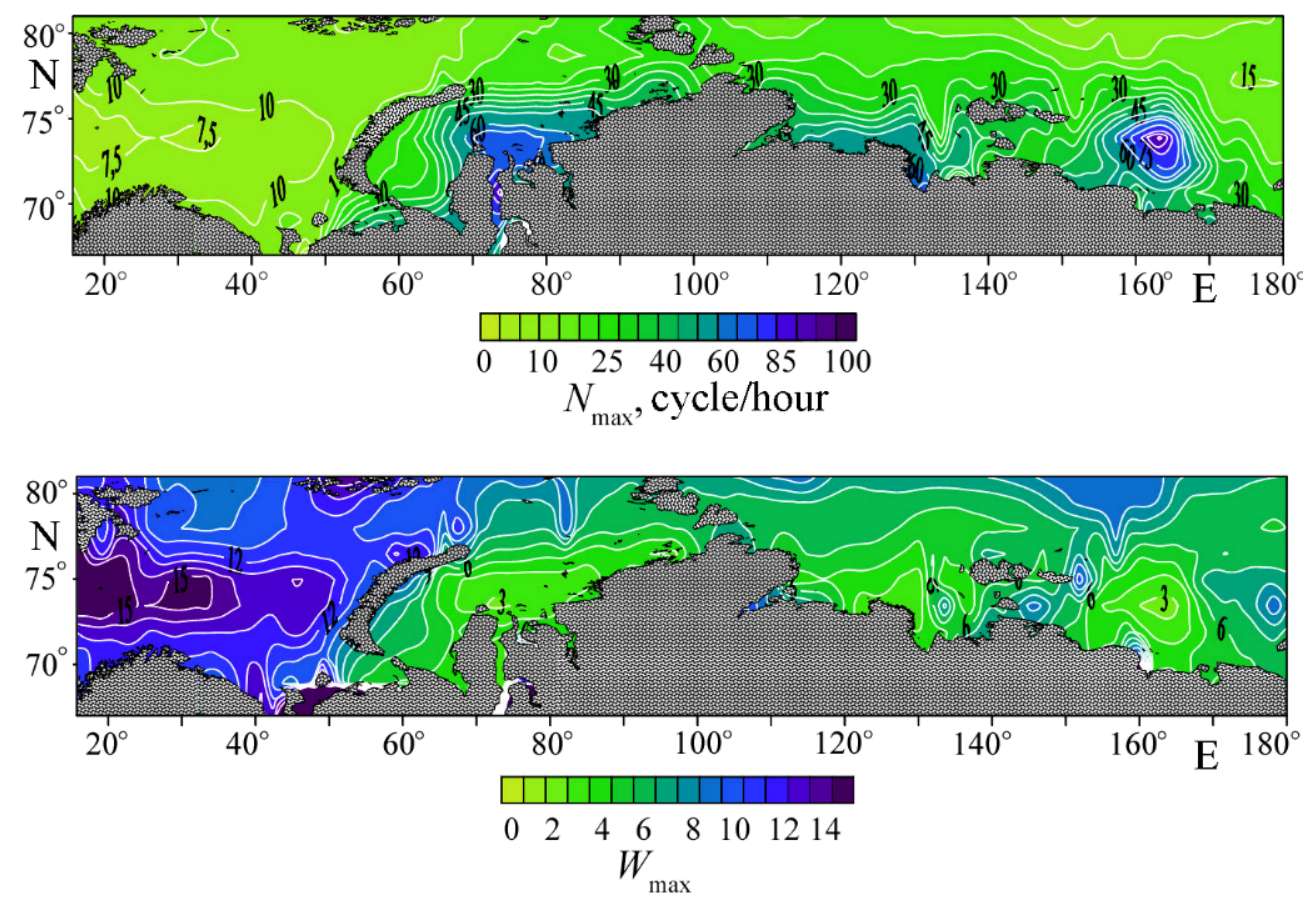

F i g. 3. Geographic distribution of maxima of the Väisälä - Brunt frequency and the amplitude of the vertical component of the IW first mode velocity (in conventional units) in August

Distribution of the Brunt - Väisälä frequency maxima and the amplitude of the vertical component of the first IW mode velocity in August is illustrated in Fig. 3, their depths are shown in Fig. 4. The waters with the greatest stability are located in coastal areas. The central and northern parts of the seas are occupied by waters with low values of the maximum buoyancy frequency. The most intense vertical wave motion of waters and the greatest depths of occurrence $N_{\max }(z)$ and $W_{\max }(z)$ are also observed there. The correlation coefficient between $N_{\max }(z)$ and 
$W_{\max }(z)$ is in the range $-0.47 \ldots-0.77$, between $H N_{\max }(z)$ and $H W_{\max }(z)-$ in the range $0.23-0.78$ (Fig. 5).
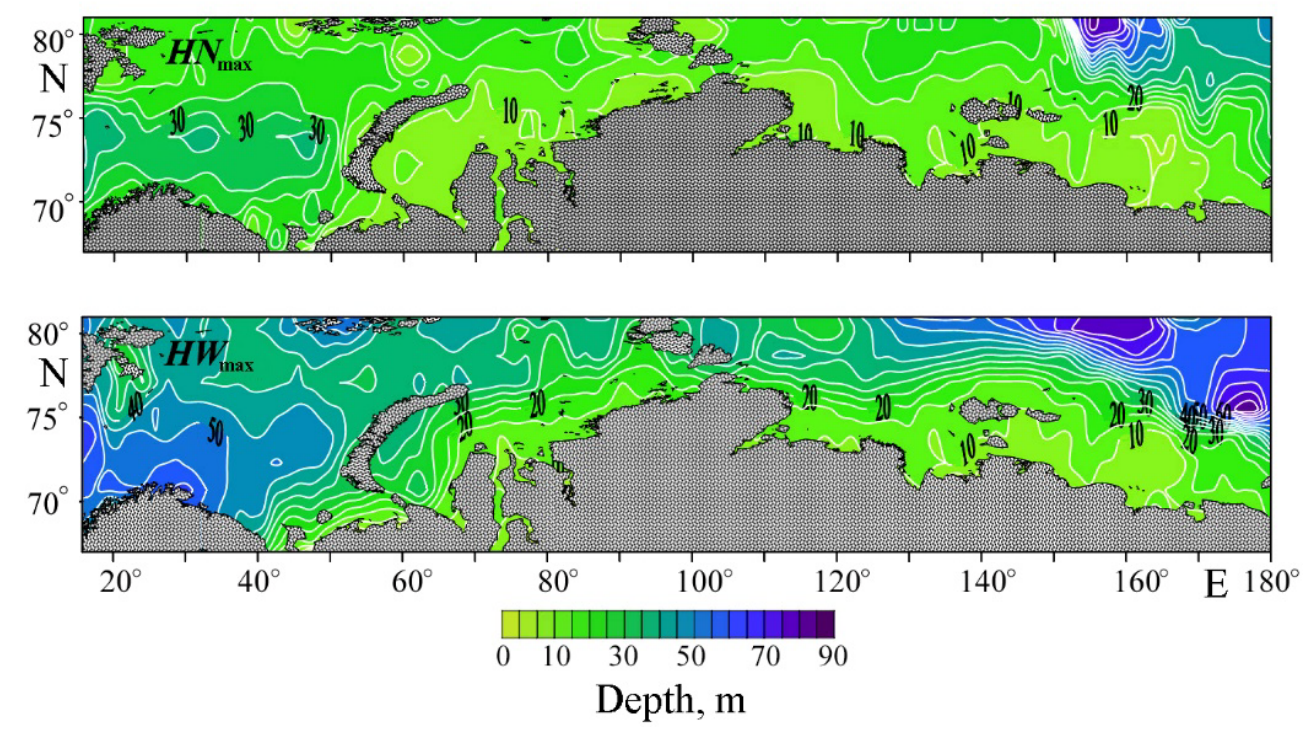

F i g. 4. Geographic distribution of depth of maxima of the Väisälä - Brunt frequency and the amplitude of the vertical component of the IW first mode velocity in August

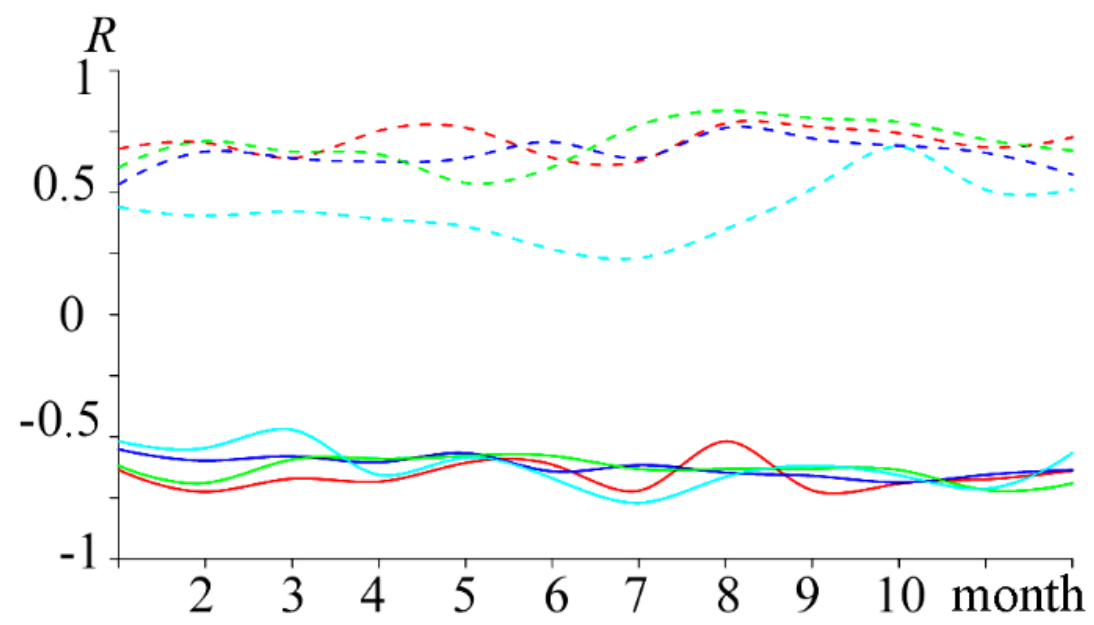

F i g. 5. Correlation coefficients between $N_{\max }$ and $W_{\max }$ (solid line), and $H N_{\max }$ and $H W_{\max }$ (dashed line) for the Barents (turquoise curve), Kara (green curve), Laptev (blue curve) and East Siberian seas (red curve) 

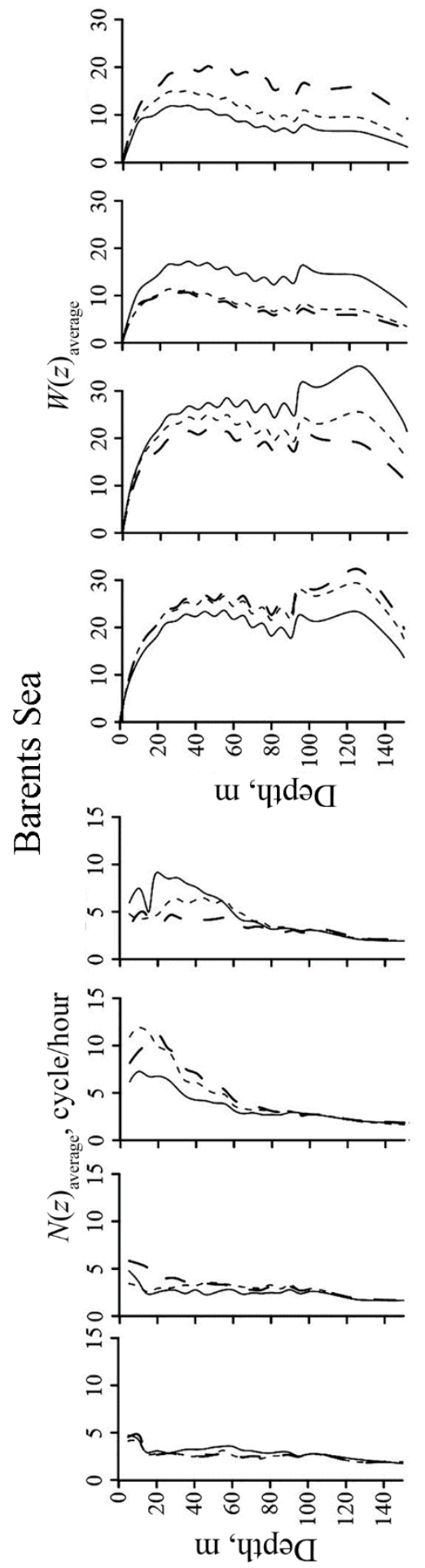
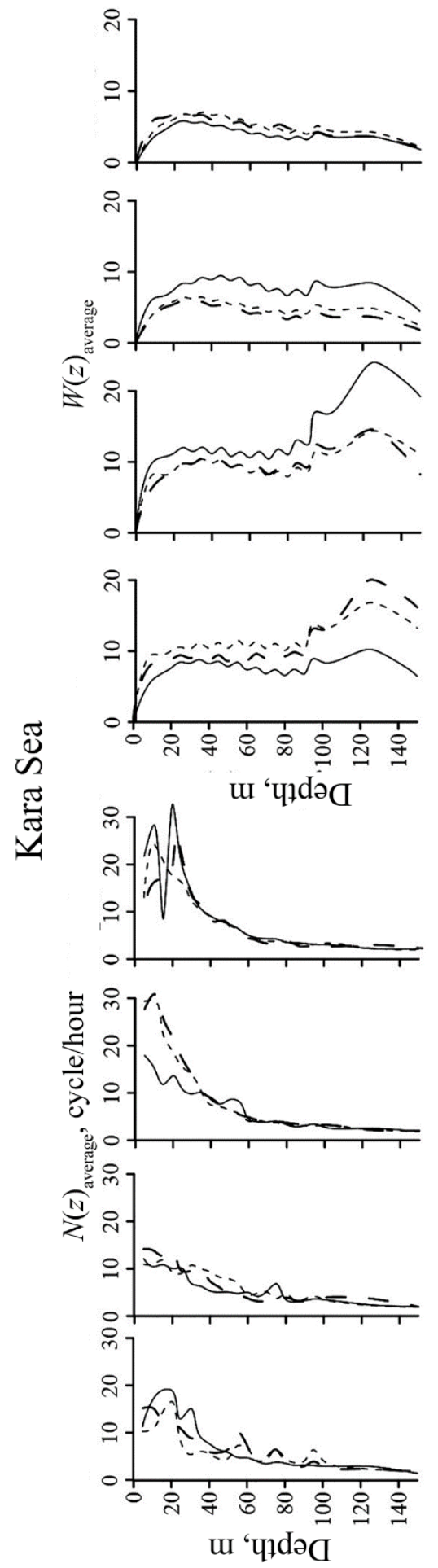

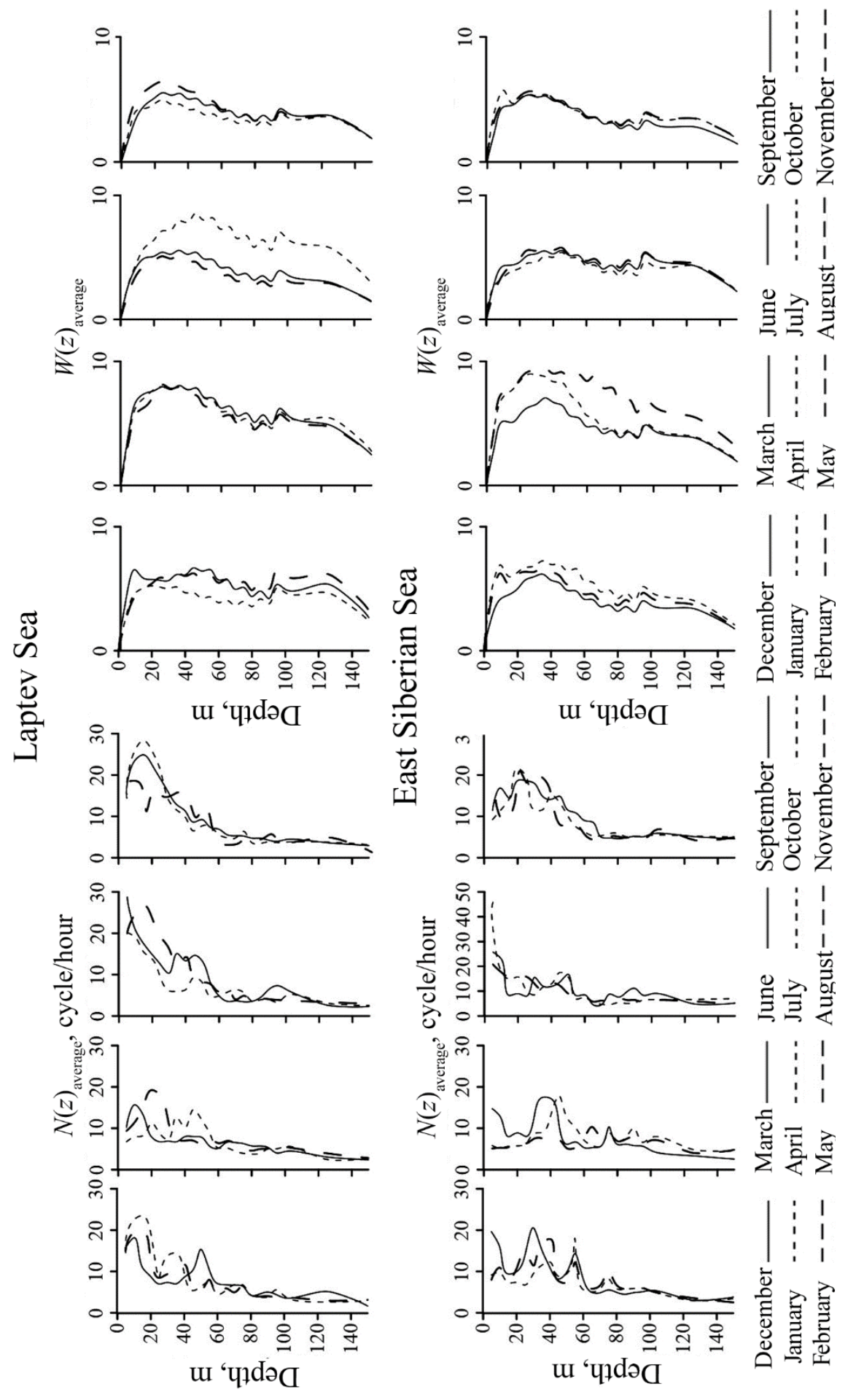

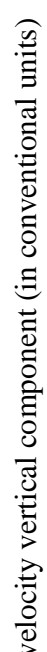
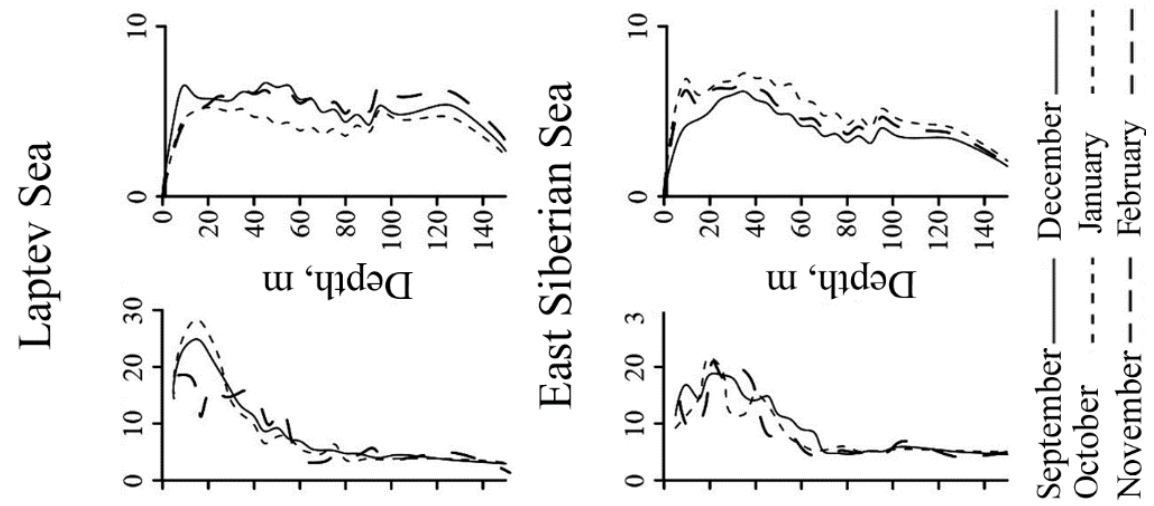

$\stackrel{8}{=}$
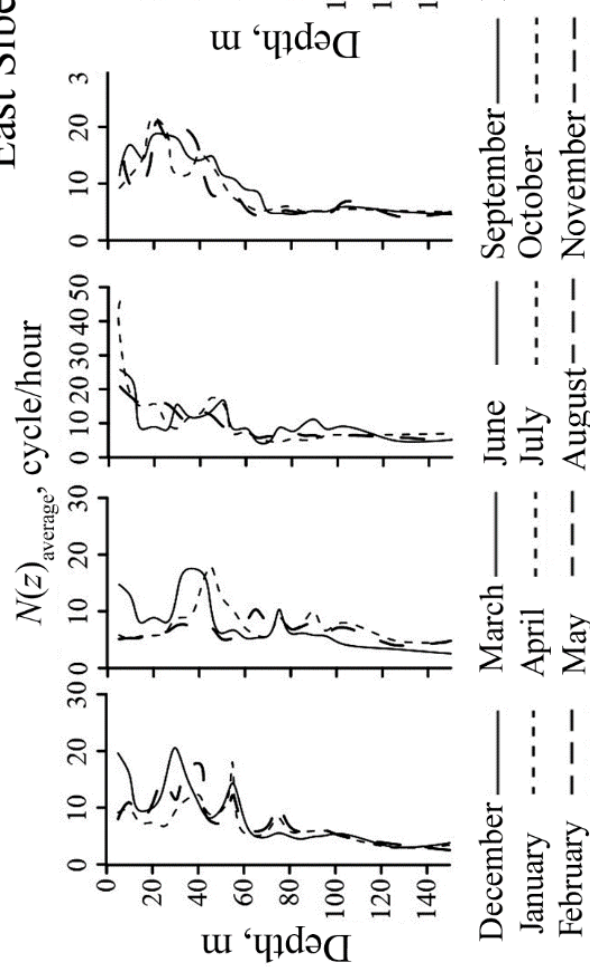
The Brunt - Väisälä frequency profiles and the amplitude of the vertical IW velocity component averaged over sea areas are shown in Fig. 6. It can be seen that the vertical density gradients in the Barents Sea are not large compared to other seas under consideration. Density jump layer is expressed from July to October, the depth of occurrence $N_{\max }(Z)_{\text {average }}$ is $20-30 \mathrm{~m}$. Throughout the year, the vertical water dynamics is developed, which is the most pronounced in winter and spring. In the Kara Sea, density jump layer remains throughout the year. Due to the large volume of the Ob-Yenisei runoff, the values of the averaged Brunt - Väisälä frequency reach 31 cycles/h. In June, a seasonal pycnocline begins to form; from July to December, the density jump layer is pronounced. The depth of occurrence of the averaged $N_{\max }(z)$ is $15-20 \mathrm{~m}$. The Brunt - Väisälä frequency profile in September has a special form. At a depth of $\sim 15 \mathrm{~m}$, a sharp decrease in $N(\mathrm{z})_{\text {average }}$ is observed, and at 20-25 m horizon the buoyancy frequency reaches its maximum. Perhaps this is due to the onset of ice formation and convective mixing in the low salinity zone [16]. Vertical wave dynamics is less developed than in the Barents Sea. However, both in the Barents Sea and in the Kara Sea, the maximum $W(z)_{\text {average }}$ values are reached in winter and spring at 120-130 m horizons. In the Laptev and East Siberian seas, due to the runoff influence of the Khatanga, Lena, Kolyma, Indigirka rivers, as well as the freshened waters of the Siberian Coastal Current, the pycnocline can be traced throughout the year. In winter, spring and summer, the pycnocline layer reaches $\sim 100 \mathrm{~m}$, in autumn $\sim 70 \mathrm{~m}$. The highest value of $N(z)_{\text {average }}$ is determined in the East Siberian Sea in July and exceeds 45 cycle/h. The vertical wave motion of waters in the Laptev and East Siberian seas is less developed than in the Barents and Kara seas (Fig. 6).

To study the dependence of the vertical structure and phase characteristics of the IW on the wavelength, the averaged values of the amplitudes of the vertical component of the velocity for $\lambda>250 \mathrm{~m}$ were calculated (Fig. 7). The calculations were carried out for deep-water areas, where $H>150 \mathrm{~m}$. It can be seen that with

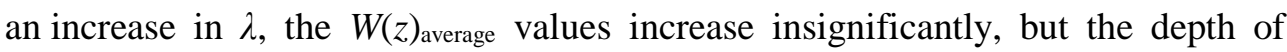
occurrence of the maximum $W(z)_{\text {average }}$ remains unchanged. The largest $W(z)_{\text {average }}$ are observed in the Barents Sea. The depth of occurrence $W_{\max }(z)_{\text {average }}$ is $\sim 90 \mathrm{~m}$ in the Barents and Kara Seas in the middle of winter and 75-80 $\mathrm{m}$ in summer, in the Laptev and East Siberian Seas $\sim 60 \mathrm{~m}$ throughout the year. The more intense vertical wave dynamics of the waters in the Barents Sea in comparison with other seas is due to the North Cape Current influence.

It can be seen (Figs. 7 and 8 ) that the averaged depths of occurrence $N_{\max }(z)$ and $W_{\max }(z)$ differ: for deep-water areas $(H>150 \mathrm{~m}) H N_{\max }(z)_{\text {average }}$ is in the layer of the seasonal pycnocline (15-40 m), $H W_{\max }(z)_{\text {average }}$ - in the main pycnocline layer (60-90 m), i.e. $H N_{\max }(z)_{\text {average }}<H W_{\max }(\mathrm{z})_{\text {average. }}$ 

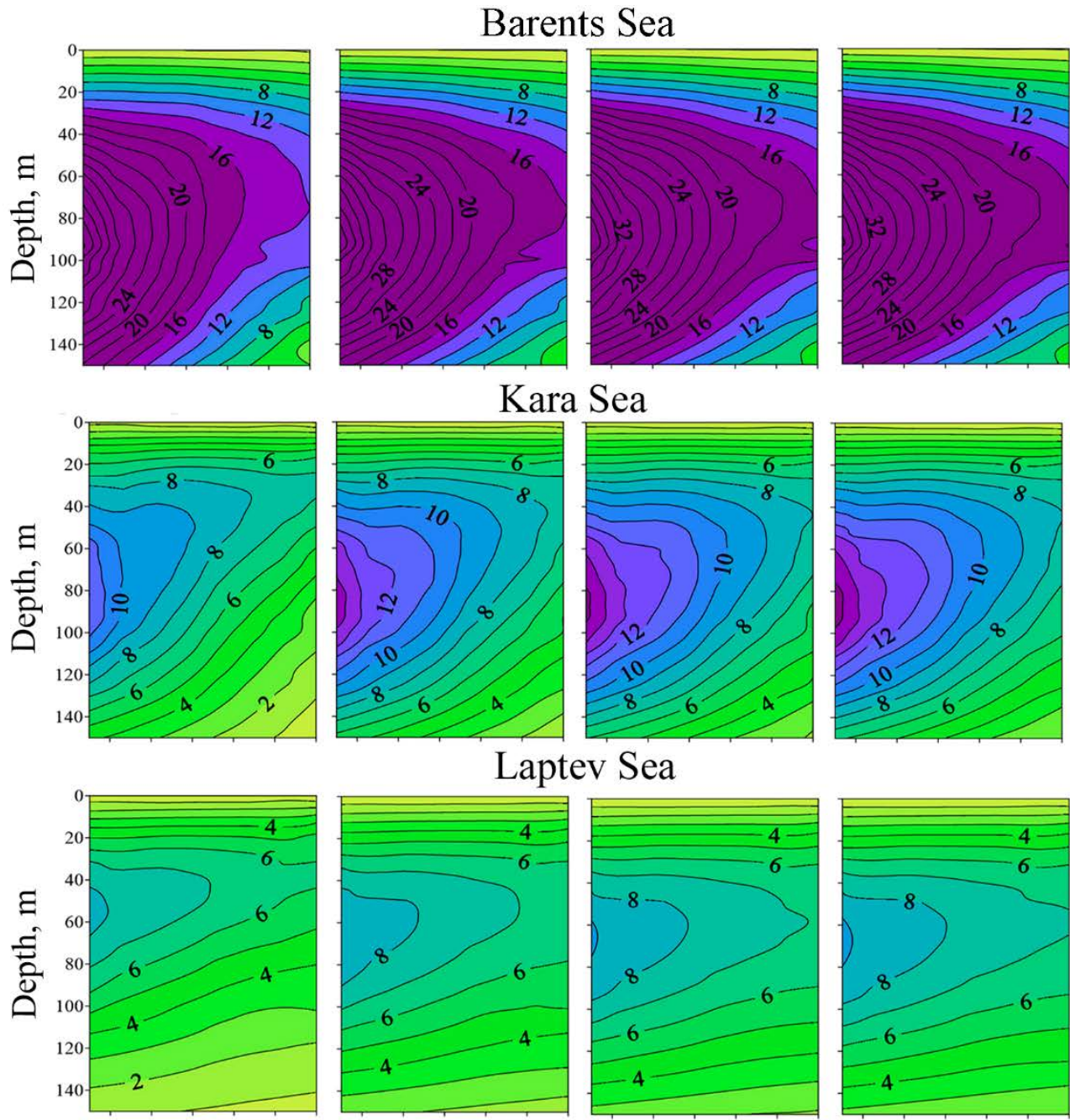

East Siberian Sea
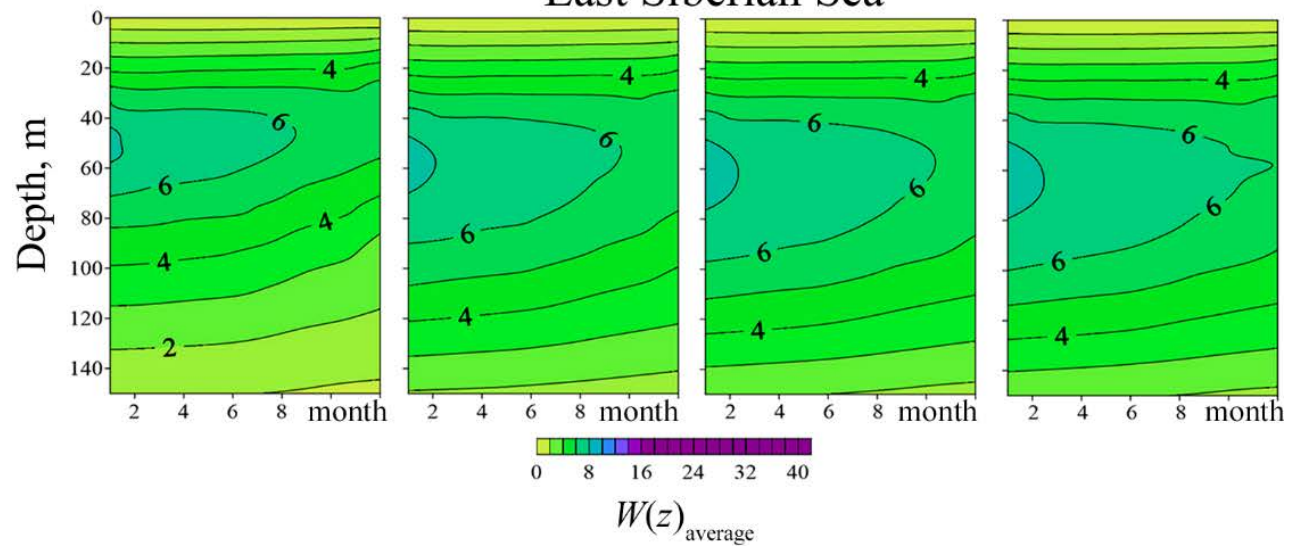

F i g. 7. Intra-annual variability of the averaged over the sea area amplitude of vertical component of the IW first mode velocity (in conventional units) at $H>150 \mathrm{~m}$ and wavelengths 250, 500, 750, $1000 \mathrm{~m}$ (from left to right) 

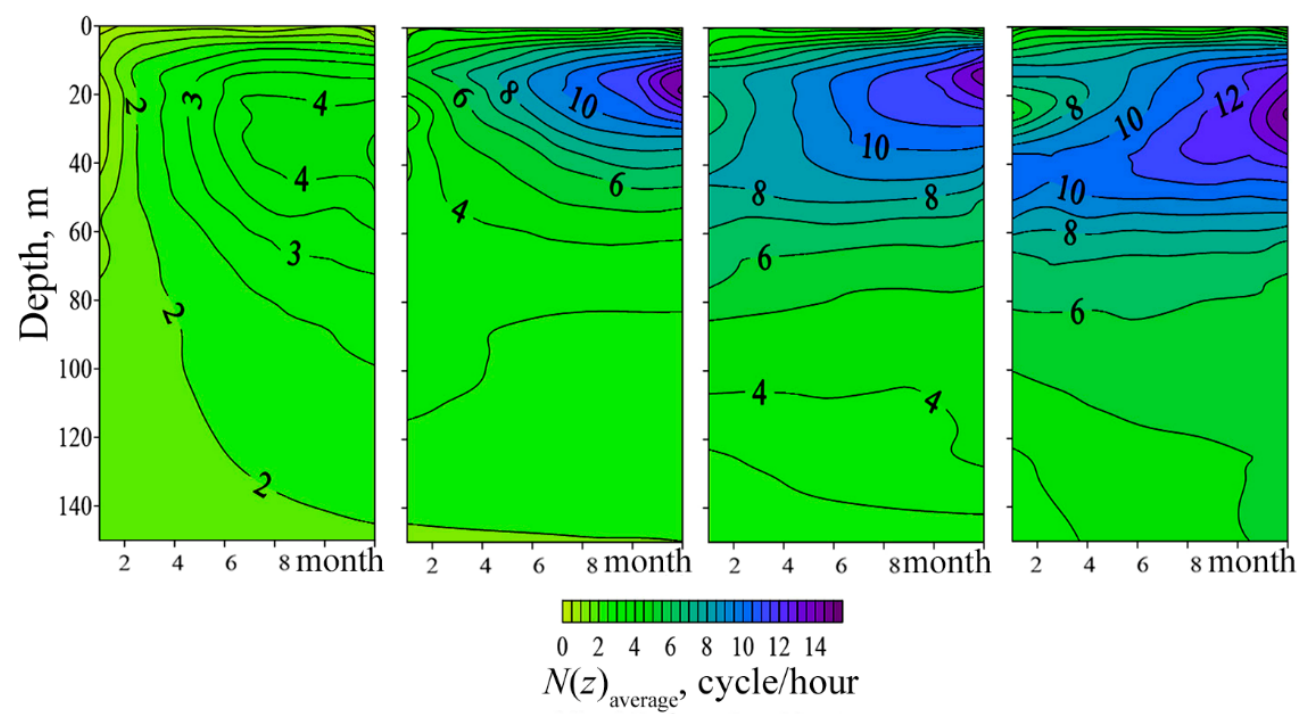

F i g. 8. Intra-annual variability of the averaged over the sea area buoyancy frequency in the Barents, Kara, Laptev and East Siberian seas (from left to right) at $H>150 \mathrm{~m}$
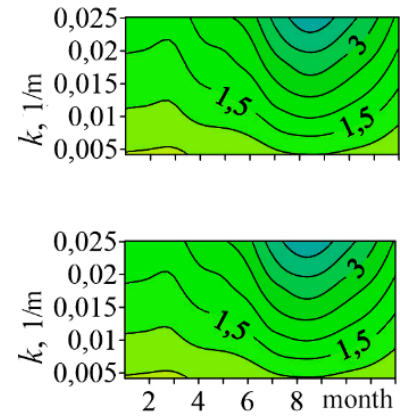
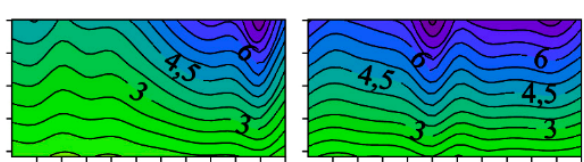

a
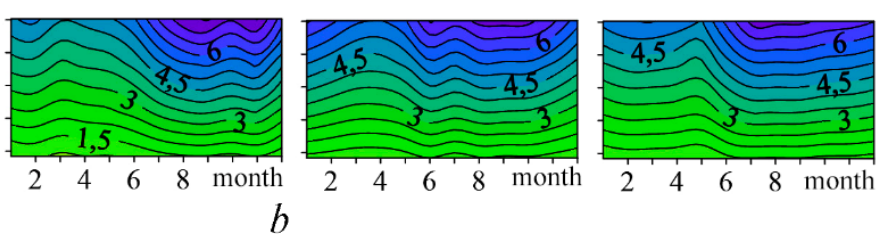

F i g. 9. Intra-annual variability of the averaged dispersion dependences of the IW first mode in the Barents, Kara, Laptev and East Siberian seas (from left to right): $a$ - at $H>150 \mathrm{~m} ; b$ - for the entire water area

Fig. 9 shows the intra-annual variability of the averaged dispersion curves of the IW first mode in the 250-1500 m wavelength range, calculated for the deepwater region (Fig. 9, $a$ ) and the entire sea area (Fig. 9, b). The averaged dispersion dependences for the Barents Sea are practically the same, because the depths with $H<150 \mathrm{~m}$ are much smaller here than in the other three seas. For the Kara, Laptev and East Siberian seas, there are insignificant discrepancies in the short-wave area. The maximum averaged own frequencies of IWs in the Barents Sea are several times lower than in other seas. 


\section{Conclusion}

Based on the World Ocean Atlas 2018 reanalysis data on temperature and salinity, an analysis of the vertical structure and dispersion properties of free internal waves was carried out and an assessment of the relationship between their characteristics and the Brunt - Väisälä frequency distribution over depth in the Barents, Kara, Laptev and East Siberian seas was fulfilled.

It is shown that the most intense dynamics of internal waves is observed in the Barents Sea. Due to the Atlantic Ocean influence, the vertical density gradients in the Barents Sea are small, and the amplitude of the vertical component of the wave velocity significantly exceeds $W(z)$ in other seas. The areas of the highest values of the amplitude of the vertical component of the velocity coincide with the areas of the lowest density gradients (central and northern areas of the seas). The correlation coefficient for sea areas between the maximum buoyancy frequency in depth and the maximum amplitude of the vertical velocity component is in the range of $-0.47 \ldots 0.77$, the correlation coefficient between the depths of their occurrence is in the range $0.23-0.78$.

The occurrence depth of the maximum amplitude of the vertical component of the IW velocity averaged over the Barents and Kara sea area is $\sim 90 \mathrm{~m}$ in the middle of winter and $\sim 75-80 \mathrm{~m}$ in summer; in the Laptev and East Siberian seas $\sim 60 \mathrm{~m}$ throughout the year. The averaged depths of the Brunt - Väisälä frequency maximum are less than the averaged depths of the maximum amplitude of the vertical velocity component.

In the months of maximum density gradients, the highest frequency and shortperiod internal waves are observed. The maximum water stability in the Barents Sea is observed in July - August, in the Kara Sea - in July - September and November, in the Laptev Sea - in June and November and in the East Siberian Sea - in July. In the same months, the maximum values of the averaged own frequencies, the minimum values of the averaged own periods and amplitudes of the vertical component of the IW velocity are observed. The correlation coefficient modulus between the Brunt - Väisälä frequency maxima averaged over sea areas and the values of own frequencies, periods and amplitudes of vertical velocities exceeds 0.9 .

\section{REFERENCES}

1. Morozov, E.G., 2018. Oceanic Internal Tides: Observations, Analysis and Modeling. Springer International Publishing AG, 304 p. https://doi.org/10.1007/978-3-319-73159-9

2. Lavrenov, I.V. and Morozov, E.G., eds., 2002. Surface and Internal Waves in the Arctic Seas. Saint-Petersburg: Gidrometeoizdat, 362 p. (in Russian).

3. Morozov, E.G. and Paka, V.T., 2010. Internal Waves in a High-Latitude Region. Oceanology, 50(5), pp. 668-674. https://doi.org/10.1134/S0001437010050048

4. Kozubskaya, G.I., Konyaev, G.V., Pludeman, A. and Sabinin, K.D., 1999. Internal Waves at the Slope of Bear Island from the Data of the Barents Sea Polar Front Experiment (bspf-92). Oceanology, 39(2), pp. 147-154.

5. Locarnini, R.A., Mishonov, A.V., Baranova, O.K., Boyer, T.P., Zweng, M.M., Garcia, H.E., Reagan, J.R., Seidov, D., Weathers, K., Paver, C.R. and Smolyar, I., 2018. World Ocean Atlas 2018. Volume 1: Temperature. NOAA Atlas NESDIS 81. Silver Spring, MD, 52 p. Available at: https://www.ncei.noaa.gov/sites/default/files/2021-03/woa18_vol1.pdf [Accessed: 31 October 2021]. 
6. Zweng, M.M., Reagan, J.R., Seidov, D., Boyer, T.P., Locarnini, R.A., Garcia, H.E., Mishonov, A.V., Baranova, O.K., Weathers, K.W., Paver, C.R. and Smolyar, I.V., 2019. World Ocean Atlas 2018. Volume 2: Salinity. NOAA Atlas NESDIS 82. Silver Spring, MD, 50 p. Available at: https:/www.ncei.noaa.gov/sites/default/files/202004/woa18_vol2.pdf [Accessed: 31 October 2021].

7. Bukatov, A.E. and Solovei, N.M., 2017. Evaluation of the Density Field Vertical Structure and the Characteristics of Internal Waves Relation with Large-Scale Atmospheric Circulation in the Peruvian and Benguela Upwelling Areas. Processes in GeoMedia, (2), pp. 485-490 (in Russian).

8. $\quad$ Krauss, W., 1966. Interne Wellen. Gerbriider Borntraeger: Berlin, 245 p. (in German).

9. Miropol'sky, Yu.Z., 2001. Dynamics of Internal Gravity Waves in the Ocean. Dordrecht: Springer, $406 \mathrm{p}$.

10. Gritsenko, V.A. and Krasitsky, V.P., 1982. On a Method for the Computation of Dispersion Relations and Eigenfunctions for Internal Waves in the Ocean from the Field Measurement Data. Okeanologia, (4), pp. 545-549 (in Russian).

11. Lobovikov, P.V., Kurkina, O.E., Kurkin, A.A. and Kokoulina, M.V., 2019. Transformation of the First Mode Breather of Internal Waves above a Bottom Step in a Three-Layer Fluid. Izvestiya, Atmospheric and Oceanic Physics, 55(6), pp. 650-661. https://doi.org/10.1134/S0001433819060094

12. Kozlov, I.E., Kudryavtsev, V.N. and Sandven, S., 2010. Some Results of Internal Waves Study in the Barents Sea Using Satellite Radar Data. Arctic and Antarctic Research, (3), pp. 60-69 (in Russian).

13. Timofeev, V.T., 1946. The Barents Sea Sustainability. Problems of the Arctic, (3), pp. 5-37 (in Russian).

14. Bukatov, A.A., Pavlenko, E.A. and Solovei, N.M., 2019. Regional Features of the Buoyancy Frequency Distribution in the Laptev and East Siberian Seas. Physical Oceanography, 26(5), pp. 387-396. doi:10.22449/1573-160X-2019-5-387-396

15. Dobrovolskiy, A.D. and Zalogin, B.S., 1982. [The Seas of USSR]. Moscow: MGU Publ., 192 p. (in Russian).

16. Doronin, Yu.P. and Heisin, D.E., 1975. [Sea Ice]. Leningrad: Gidrometeoizdat, 319 p. (in Russian).

About the authors:

Anton A. Bukatov, Leading Research Associate, Marine Hydrophysical Institute of RAS (2 Kapitanskaya Str., Sevastopol, 299011, Russian Federation), Ph. D. (Phys.-Math.), ORCID ID: 0000-0002-1165-8428, ResearcherID: P-6733-2017, newisland@list.ru

Nelya M. Solovei, Junior Research Associate, Marine Hydrophysical Institute of RAS (2 Kapitanskaya Str., Sevastopol, 299011, Russian Federation), ORCID ID: 0000-0003-3359-0345, ne.le.7@hotmail.com

Ekaterina A. Pavlenko, Junior Research Associate, Marine Hydrophysical Institute of RAS (2 Kapitanskaya Str., Sevastopol, 299011, Russian Federation), ORCID ID: 0000-0001-9146-5708, mhi.pavlenko@gmail.com

Contribution of the co-authors:

Anton A. Bukatov - statement of the problem, analysis of the research data, analysis and revision of the text

Nelya M. Solovei - development of the program algorithms, analysis of the results of numerical experiments, correction of the paper, reviewing the literature

Ekaterina A. Pavlenko - analysis and validation of results, preparation of graphic materials, preparation of the paper text

All the authors have read and approved the final manuscript.

The authors declare that they have no conflict of interest.

PHYSICAL OCEANOGRAPHY VOL. 28 ISS. 6 (2021) 